\title{
REFLECTION
}

\section{The Mid-Career Demon}

\section{Timothy P. Daaleman, DO, MPH}

Department of Family Medicine, University of North Carolina at Chapel Hill, Chapel Hill, North Carolina
Conflicts of interest: author reports none.

\section{CORRESPONDING AUTHOR}

Timothy P. Daaleman, DO, MPH

Department of Family Medicine

University of North Carolina at Chapel Hill

Campus Box 7595

Chapel Hill, NC 275199-7595

tim_daaleman@med.unc.edu

\begin{abstract}
For several months I have been trying to tag a greyness that has shaded my doctoring. I was not burned out but uncovered the desert experience of mind and soul known as acedia, which is called the noonday demon because it vexes those in the mid-stages of life. Grappling with the noonday demon has upended all of my assumptions about the workings of hope in the practice of medicine. For me, hope is no longer the anticipation of a positive outcome, or the warm feeling associated with the validation of a correct diagnosis, or the conclusion of successful treatment. I am beginning to realize that hope is the pulse of caregiving beating in me-and in the heart of every physician-which first stirs when I am with a patient, and then propels me forward in all of my doctoring.
\end{abstract}

Ann Fam Med 2018;16:264-266. https://doi.org/10.1370/afm.2232.

$\mathrm{T}$ There is a great disturbance in the healing force of medicine. Burnout has increased by nearly $10 \%$ in recent years and more than one-half of US physicians now report experiencing at least one burnout symptom, such as emotional exhaustion or depersonalization. ${ }^{1}$ Physician groups, clinics, and hospitals are exploring ways to redress the emotional and spiritual holes that are left across the health care landscape due to this malady. The academic medical center where I work, for example, has encouraged physicians to complete an anonymous online survey that seeks to identify burnout, and to connect those who are at risk with resources. When I completed the survey, I was both reassured and disappointed to find that my risk of burnout was average, and that my scores for "meaning at work" and "work/life balance" were comparable to my peers.

The survey fell short of my expectations because I was hoping that the results would tag a greyness that has shaded my doctoring over the last several months. In hindsight, one indicator of the greyness was a subconscious decision to cut back on my social visits to patients who were hospitalized, a responsibility that I had regularly enjoyed. On some level, my clinical inertia may have stemmed from grieving for several longstanding, chronically ill patients who died, not unexpectedly, in this timeframe. Another root cause could have been the fallout from my own age-related changes - hip replacement and back surgeries notwithstanding - that forced me to consider my health as no longer excellent. In the midst of these professional and personal challenges, I wondered what was next for me as a physician, triggering a hard look back at my profession, and a sorting of my desires about practicing medicine.

Because I was not technically classified as burned out, I looked to other disciplines and traditions for alternative ways to understand my experience. I came across the concept of acedia, an infirmity that strikes those who try to stay true to a committed life. ${ }^{2}$ I first learned about acedia nearly a decade ago through author Kathleen Norris ${ }^{2}$ and found that her depiction of this condition, and application to her life experience, resonated with my own. Acedia shares some common features with burnout since its Greek root means the absence of care; the person suffering with acedia refuses to, or is incapable of, caring. ${ }^{2}$ Norris grounds an understanding of acedia in the 
4th-century work of Evagrius Ponticus, who wrote from the perspective of monastic life.

The demon of acedia is the one that causes the most serious trouble of all. First, he makes it seem that the sun barely moves and that the day is fifty hours long. Then he instills in the heart a hatred for the place and a hatred for life itself. The demon leads him to reflect that charity has departed from his brethren and that there is no one to give encouragement. Should there be someone who happens to offend him in some way, this too the demon will use to further his hatred. This demon drives him along to desire other places where he can more easily procure life's necessities, more readily find work, and make a real success of himself. ${ }^{2}$

Acedia is the desert experience for mind and soul, and it is known as the noonday demon because it vexes those who are in the mid-stages of life. ${ }^{2}$ This unempirical characterization intrigued me, and I revisited the physician burnout data to learn that mid-career physicians do report the lowest satisfaction with their specialty choice and work-life balance, as well as the highest rates of emotional exhaustion and burnout. ${ }^{3}$ In addition, physicians who experience burnout no longer find their work rewarding, no longer see their work as one of the most important things in their lives, and no longer believe that their work makes the world a better place. ${ }^{4}$

The literature review led me to consider if burnout and acedia are part of a larger continuum of professional and personal challenges that doctors may face across their careers. At one end are the substance use and mood disorders that can afflict clinicians, struggles that are often helped by physician health programs. ${ }^{5,6}$ At the other end are the intermittent interpersonal and psychological strains that can be due to disruptive organizational changes in practice, ${ }^{7}$ and from either anticipated or unexpected transitions that arise at different points in our life course. ${ }^{8}$ I am somewhere in the middle of this spectrum, a place where the noonday demon of acedia has shown up in different ways to try and lay my professional soul to waste.

Although I can still appreciate the ample resources in my clinical environment and the commitment of the support staff to patient care, the demon on my shoulder has called out times when there were faults in our collective caregiving, whispering to me that there are better practice settings out there. My colleagues are excellent clinicians who care for my family and me. But the demon in my head fixated on occasions of poor documentation and miscommunication as pretexts that riled me into questioning their clinical decisions and treatment plans for my patients as ill-reasoned and suspect. The demon who wreaked the most havoc and destruction was in my heart, where he shouted out that none of my doctoring mattered in the lives of my patients. His dismal refrain was that the progression of chronic disease would continue regardless of my care, and that their long march to death would be marked by misery, brokenness, and alienation.

I am starting to see light in the midst of such darkness.

According to Evagrius, peace and joy will come to those who can subdue the demon of acedia. ${ }^{2}$ Although I do not believe in demons, I am realizing that this future state is tied to hope. As a physician, I previously thought of hope as a sense of expectancy for a positive outcome, such as the resolution of an acute and treatable illness, the abatement of symptoms for those with chronic disease, or a good death at the end of life. Grappling with the noonday demon has upended all of these assumptions, challenging my long-held ideas and beliefs about the workings of hope in the practice of medicine. In its place, I am catching glimpses of a radically different way of thinking and practicing, an understanding of hope that comes through in a subtle, but unmistakable quality of aliveness ${ }^{9}$ that takes hold of me during unexpected patient encounters.

A few weeks ago I had an appointment with a longstanding patient who underwent a lung biopsy for a worrisome lesion found on a CT scan that I had ordered. The pathology report confirmed a malignancy and she was in the process of completing further imaging for staging, before meeting with the cancer team to discuss treatment. At her follow-up visit I began by recapping the clinical presentation-a persistent cough and weight loss in the setting of a longstanding history of cigarette smoking-before reviewing the radiographic and diagnostic studies which definitively showed that she had lung cancer. I felt that I was compassionate and effective in communicating the bad news. My mind, however, had already gone down a prognostic rabbit hole of how my patient's disease course would play out; an initial period of outpatient treatment followed by a spiral of repeated hospitalizations, and then palliative care, and then death. At the end of my comments she paused for a moment and smiled at me with a single comment: "We'll be aw' right."

Her spare declaration jerked me clean out of that hole; it was not "I will be all right", but "we will be all right." In the face of a newly disclosed cancer, an uncertain treatment course, and the specter of death, she was not just voicing words of self-reassurance ${ }_{i}$ my patient was pulling me out of myself and into her lived experience, into the space of her hope.

For me, hope is no longer the ongoing anticipation of an expected outcome, or the warm feeling that is associated with either the validation of a correct 
diagnosis or the conclusion of successful treatment. Hope lies, rather, at the beginning of doctoring. It is that pulse of caregiving - beating in the heart of every physician - which first stirs within us, and then propels us forward in all of our actions. ${ }^{9}$ As a mid-career physician I am beginning to understand that moving from acedia to hope is tied to a capacity to trust, which is what we have asked patients to place in us. This movement will be apparent when I can recognize, and not deny, those incandescent patient care encounters as authentic and enduring. Trust will be also be gauged by my willingness to let go of old ways of practicing medicine, so that I can see the clinical setting in front of me as a new therapeutic landscape. At some point, however, I will know that hope has vanquished that demon of acedia when I can readily look beyond the day-to-day challenges of difficult and sometimes painful clinical moments-when nothing I do seemingly matters-and believe that my care is part of a greater, healing force of medicine.

To read or post commentaries in response to this article, see it online at http://www.AnnFamMed.org/content/16/3/264.

Submitted July 27, 2017; submitted, revised, October 30, 2017; accepted November 29, 2017

\section{References}

1. Shanafelt TD, Hasan O, Dyrbye LN, et al. Changes in burnout and satisfaction with work-life balance in physicians and the general US working population between 2011 and 2014. Mayo Clin Proc. 2015: 90(12):1600-1613.

2. Norris K. Acedia \& Me : A Marriage, Monks, and a Writer's Life. New York, NY: Riverhead Books; 2008.

3. Dyrbye LN, Varkey P, Boone SL, Satele DV, Sloan JA, Shanafelt TD. Physician satisfaction and burnout at different career stages. Mayo Clin Proc. 2013;88(12):1358-1367.

4. Jager AJ, Tutty MA, Kao AC. Association between physician burnout and identification with medicine as a calling. Mayo Clin Proc. 2017; 92(3):415-422.

5. Mata DA, Ramos MA, Bansal N, et al. Prevalence of depression and depressive symptoms among resident physicians: a systematic review and meta-analysis. JAMA. 2015;314(22):2373-2383.

6. Rose JS, Campbell MD, Yellowlees P, Skipper GE, DuPont RL. Family medicine physicians with substance use disorder: a 5 -year outcome study. J Addict Med. 2017;11(2):93-97.

7. Arndt BG, Beasley JW, Watkinson MD, et al. Tethered to the EHR: primary care physician workload assessment using ehr event log data and time-motion observations. Ann Fam Med. 2017;15(5):419-426

8. Hoff T, Young G, Xiang E, Raver E. Understanding US physician satisfaction: state of the evidence and future directions. J Healthc Manag. 2015;60(6):409-427.

9. Bourgeault C. Mystical Hope. Cambridge, MA: Cowley Publications; 2001.

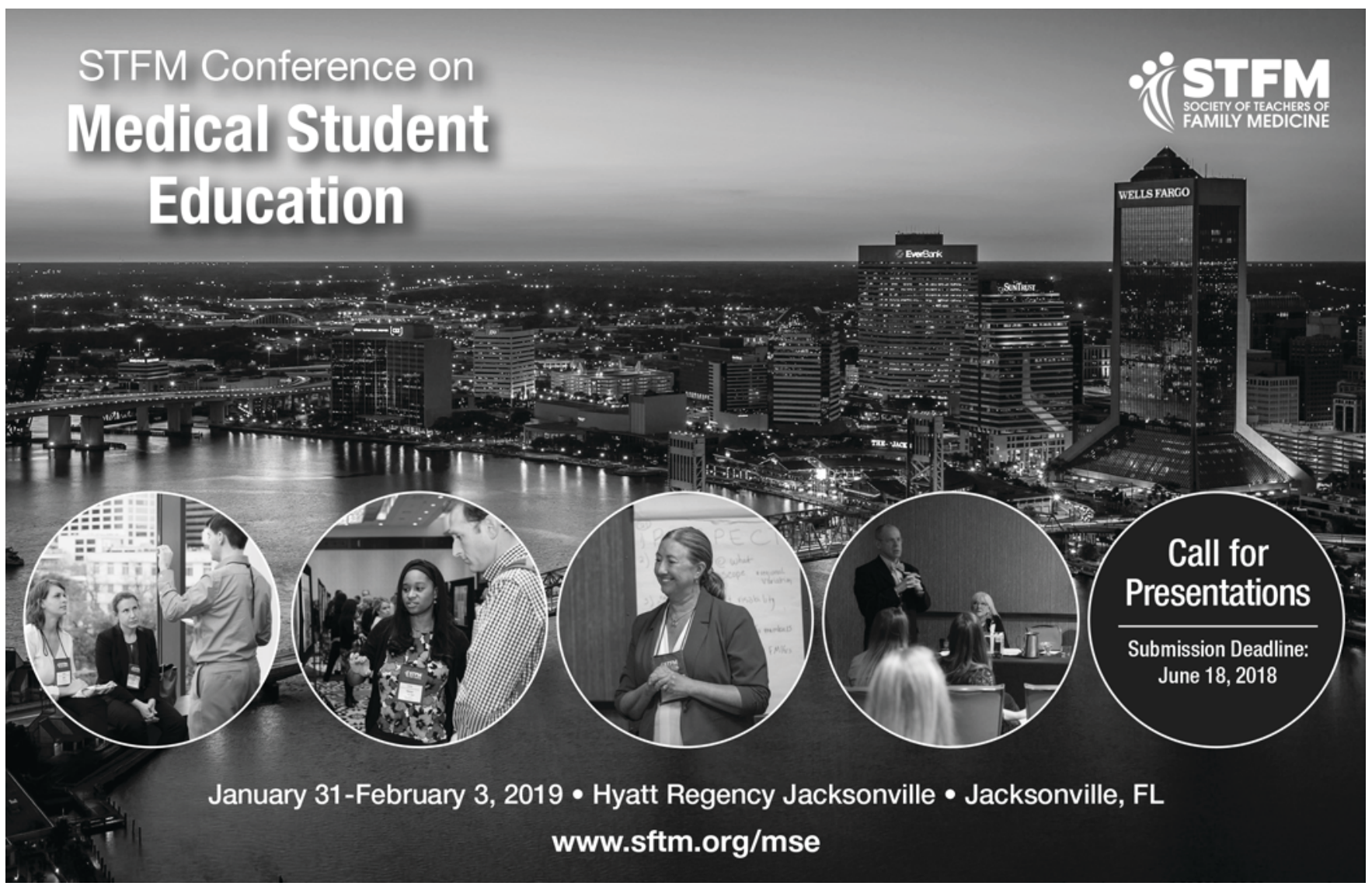

ANNALS OF FAMILY MEDICINE + WWW.ANNFAMMED.ORG + VOL. 16, NO. 3 + MAYIJUNE 2018 